\title{
Laparoskopisk biliopankreatisk avledning med duodenal omkobling ved sykelig fedme
}

\begin{abstract}
Sammendrag
Bakgrunn. Biliopankreatisk avledning med duodenal omkobling benyttes ved behandling av sykelig fedme. Få sentre utfører inngrepet laparoskopisk. Vi $ø$ nsket å evaluere perioperative resultater og vektutvikling etter laparoskopisk duodenal omkobling.

Materiale og metode. Alle pasienter operert med duodenal omkobling ved Senter for sykelig overvekt i Helse Sør-Øst, Oslo universitetssykehus, fra juni 2004 til og med desember 2009. ble inkludert. Perioperativ periode ble definert som innen 30 dager etter operasjonen.
\end{abstract}

Resultater. 48 pasienter ble operert. Median preoperativ kroppsmasseindeks (BMI) var $54 \mathrm{~kg} / \mathrm{m}^{2}$ (spredning $41-88 \mathrm{~kg} / \mathrm{m}^{2}$ ) og 33 pasienter (69\%) var kvinner. Ti pasienter (21\%) fikk først utført langsgående ventrikkelreseksjon og senere duodenal omkobling. Alle inngrepene ble fullført laparoskopisk. Median operasjonstid var $200 \mathrm{~min}$ (spredning 100-658 min). 12 pasienter (25\%) utviklet komplikasjoner, fire (8\%) ble reoperert, en døde. Median liggetid i sykehus var tre dager (spredning 1-56 dager) Median kroppsmasseindeks etter to år var $32 \mathrm{~kg} / \mathrm{m}^{2}$ (spredning $24-45 \mathrm{~kg} / \mathrm{m}^{2}$ ), tilsvarende en median vektreduksjon på $39 \%$ (spredning $22-60 \%$ ) og $73 \%$ (spredning 43-106) tap av preoperativ kroppsmasseindeks over $25 \mathrm{~kg} / \mathrm{m}^{2}$.

Fortolkning. Duodenal omkobling utføres hos en liten andel pasienter operert for sykelig fedme. Inngrepet kan utføres laparoskopisk med kort liggetid og medfører et betydelig vekttap. Komplikasjonsfrekvensen var høy og sammenliknbar med andre studier.

\section{Carl Fredrik Schou}

carl.fredrik.schou@akersykehus.no Torgeir T. Søvik

Senter for sykelig overvekt i Helse Sør-Øst og

Gastroenterologisk kirurgisk avdeling

Oslo universitetssykehus, Aker

\section{Erlend T. Aasheim}

Imperial Weight Centre, Imperial College London, England

\section{Jon Kristinsson}

Tom Mala

Senter for sykelig overvekt i Helse Sør-Øst og

Gastroenterologisk kirurgisk avdeling

Oslo universitetssykehus, Aker

Kirurgisk behandling av sykelig fedme fører til langvarig vektreduksjon og bedring av vektrelaterte tilleggsykdommer og helserelatert livskvalitet (1-4). Laparoskopisk gastrisk bypass er hovedmetode ved slik behandling i Norge (4). Livsstilsintervensjon medfører sjelden vektreduksjon som holder seg over tid hos denne pasientgruppen. Nærmere $20 \%$ av den norske befolkning har utviklet fedme dvs. kroppsmasseindeks (BMI) over $30 \mathrm{~kg} / \mathrm{m}^{2}$ (5), mens det er anslått at $1 \%$ kan ha sykelig fedme hvor kirurgi kan være indisert. I USA har det vært en sterk økning av forekomsten av svært høy kroppsmasseindeks (6).

Mer enn halvparten av pasientene med BMI $>50 \mathrm{~kg} / \mathrm{m}^{2}$ før gastrisk bypass har BMI $>35 \mathrm{~kg} / \mathrm{m}^{2}$ flere år etter operasjonen (7). En annen operasjon, biliopankreatisk avledning med duodenal omkobling (duodenal omkobling), gir større vekttap enn gastrisk bypass $(8,9)$. Det er imidlertid usikkert om dette ekstra vekttapet også er assosiert med ytterligere bedring av fedmerelaterte tilleggsykdommer. Duodenal omkobling medfører dessuten malabsorpsjon og er forbundet med risiko for malnutrisjon $(10,11)$. Duodenal omkobling er en teknisk krevende prosedyre og få sentre utfører operasjonen laparoskopisk. Flere studier har vist at metoden er assosiert med høy komplikasjonsrate.

Vi beskriver her våre perioperative erfaringer med laparoskopisk duodenal omkobling, samt vektutvikling etter inngrepet.

\section{Materiale og metode}

I perioden fra 1.6. 2004 til og med 31.12. 2009 ble det operert 890 pasienter for sykelig fedme ved Senter for sykelig overvekt i Helse Sør-Øst, Oslo universitetssykehus,
Aker. Alle pasienter operert med duodenal omkobling i denne perioden ble inkludert $\mathrm{i}$ denne artikkelen. En pasient, for hvem det var planlagt duodenal omkobling, men som bare fikk utført diagnostisk laparoskopi på grunn av omfattende peritoneale sammenvoksninger, ble avvist for fedmekirurgi og ekskludert. Pasientene operert til og med desember $2005(n=13)$ er identifisert ved gjennomgang av operasjonsprotokoll, og data er retrospektivt registrert. Senere er pasientdata prospektivt registrert.

Indikasjon for fedmekirurgisk behandling er sykelig fedme, dvs. BMI $\geq 35 \mathrm{~kg} / \mathrm{m}^{2}$ med samtidig vektrelatert tilleggssykdom eller $\mathrm{BMI} \geq 40 \mathrm{~kg} / \mathrm{m}^{2}$, dersom konservative tiltak for vektnedgang er forsøkt. Ved vårt senter vurderes duodenal omkobling vanligvis kun hos pasienter med BMI $\geq 50 \mathrm{~kg} / \mathrm{m}^{2}$.

Pasientene ble vurdert av klinisk ernæringsfysiolog, sykepleier og kirurg før operasjonen. De deltok også ved et obligatorisk kurs ved Lærings- og mestringssenteret ved Oslo universitetssykehus, Aker. Her fikk de blant annet kostholdsveiledning og informasjon om behandlingen. Pasientene fulgte en lavkaloridiett (4 $184 \mathrm{~J}$ (1 $000 \mathrm{kcal}$ )/døgn) de siste tre ukene før operasjonen.

\section{Kirurgisk metode}

Alle prosedyrene med duodenal omkobling ble utført av samme hovedoperatør, bortsett fra en, der denne var assistent. Assistenten har stort sett vært samme person med få unntak, og denne var hovedoperatør ved en prosedyre. Ved duodenal omkobling (fig 1) gjøres en partiell langsgående gastrektomi (gastric sleeve). Duodenum deles like distalt for pylorus og anastomoseres til ileum (duodenal omkobling). Tynntarmen får dermed to separate løp: et alimentært løp for føde og et biliopankreatisk løp for galle og pankreassekret. De siste $100 \mathrm{~cm}$ før coecum føres disse to løpene sammen i et fellesløp. Det ble gitt peroperativ antibiotikaprofylakse.

\section{Hovedbudskap}

- Duodenal omkobling er et behandlingsalternativ ved sykelig fedme

- Operasjonen benyttes vanligvis ved spesielt høy kroppsmasseindeks

- Inngrepet kan utføres laparoskopisk med kort liggetid i sykehus og fører til betydelig vekttap 
Duodenal omkobling ble hos noen av de tyngste pasientene utført i to seanser. Ved slike totrinnsprosedyrer ble det først gjort en langsgående ventrikkelreseksjon. Etter et initialt vekttap ble så den duodenale omkoblingen utført. Hos de første pasientene ble det gjort kolecystektomi og appendektomi som del av inngrepet.

\section{Postoperativ oppfølging}

Pasientene fikk høydose lavmolekylært heparin operasjonsdagen og i til sammen ti dager etter utskrivning. De ble tilbudt drikke få timer postoperativt og mobilisert samme dag. Før utskrivning fra sykehuset ble det gitt tilbud om samtale med klinisk ernæringsfysiolog. Flytende kost ble anbefalt i en uke og deretter most mat $i$ to uker før normal kost ble gradvis introdusert. Alle pasientene fikk standard substitusjonsbehandling med multivitamin, jern og kalsium med vitamin D. Ursodeoksykolsyre ble forskrevet i seks måneder for å redusere risikoen for gallestein til alle pasienter som ikke hadde fått utført kolecystektomi. Pasientene ble tilbudt kontroll hos klinisk ernæringsfysiolog og/ eller lege seks uker, seks måneder, ett år, to år og fem år etter operasjonen. De ble oppfordret til å kontakte fastlege for oppfølging av tilleggssykdommer som hypertensjon og diabetes.

\section{Databehandling}

Komorbiditet før operasjonen ble registrert ved legekonsultasjon på standardisert skjema utarbeidet ved avdelingen, basert på opplysninger fra henvisende lege, anamnese, klinisk undersøkelse og blodprøver. Perioperativ periode ble definert som under sykehusoppholdet eller innen 30 dager etter operasjonen. For totrinnsprosedyrer er operasjonstiden kun angitt for inngrepet hvor duodenal omkobling ble utført. Vektdata ble registrert ved alle postoperative konsultasjoner, og data for vektutvikling ble gjort opp januar 2010. Vekttapet er regnet ut med utgangspunkt i preoperativ vekt hos pasientene som møtte til kontroll. Vekttapet presenteres som antall kilo vekttap og i prosent reduksjon av kroppsmasseindeks over $25 \mathrm{~kg} / \mathrm{m}^{2}$, dvs (preoperativ BMI-aktuell BMI)/(preoperativ BMI-25) $\times 100(12)$. I tillegg angis vekttap i prosent av utgangsvekten.

Pasientopplysninger ble lagret $i$ en database (Microsoft Office Access) med konsesjon fra Datatilsynet. Alle pasienter har gitt skriftlig samtykke til publisering. Pårørende til pasienten som døde, har gitt samtykke til at opplysninger publiseres. Kontinuerlige data angis som median med spredning.

\section{Resultater}

Duodenal omkobling ble utført hos 48/890 pasienter $(5 \%)$ operert for sykelig fedme i perioden. Median alder hos disse 48 pasientene var 36 år (17-54 år) og 33 av pasientene $(69 \%)$ var kvinner. Median kroppsmasseindeks var $54 \mathrm{~kg} / \mathrm{m}^{2}\left(41-88 \mathrm{~kg} / \mathrm{m}^{2}\right)$ ved preoperativ konsultasjon hos kirurg. Preoperativ komorbiditet er vist i tabell 1 .

Ti pasienter (21\%) ble operert i to seanser (totrinnsprosedyrer). Median preoperativ kroppsmasseindeks hos disse var $63 \mathrm{~kg} / \mathrm{m}^{2}$ $\left(41-88 \mathrm{~kg} / \mathrm{m}^{2}\right)$. Median vektreduksjon var $24 \mathrm{~kg}(3-74 \mathrm{~kg})$ mellom første og andre operasjon, en gikk opp i vekt. Median tid mellom de to operasjonene var $16 \mathrm{md}$. (7-36 md.).

Alle inngrep ble fullført laparoskopisk. Sju pasienter fikk utført kolecystektomi og fem appendektomi samtidig med duodenal omkobling. Hos en ble det foretatt peroperativ gastroskopi fordi man lurte på om den duodenoileoanale anastomosen ble for tett. Median operasjonstid for duodenal omkobling var $200 \mathrm{~min}$ (100-658 min). Tiden ble kortere når teamet fikk erfaring med metoden (fig 2).

12 pasienter $(25 \%)$ utviklet komplikasjoner innen 30 dager etter operasjon ( $\operatorname{tab} 2$ ).
Fire $(8 \%)$ ble reoperert innen 30 dager, alle primært laparoskopisk. En av disse ble reoperert flere ganger også ved laparotomi, og døde som følge av lekkasje fra den duodenoileoanale anastomosen, med intraabdominal infeksjon, sepsis og multiorgansvikt. Seks pasienter $(13 \%)$ ble reinnlagt innen 30 dager, hvorav en ved et annet sykehus (tab 2). Median postoperativ liggetid i sykehus var tre dager (1-7 dager) etter isolert langsgående ventrikkelreseksjon (ti pasienter) og tre dager (1-56 dager) etter duodenal omkobling.

Median observasjonstid for vektutvikling var 24 md. (1-50 md.) (fig 3). Median kroppsmasseindeks ett og to år etter duodenal omkobling var henholdsvis $34 \mathrm{~kg} / \mathrm{m}^{2}(25-54$ $\left.\mathrm{kg} / \mathrm{m}^{2}\right)$ og $32 \mathrm{~kg} / \mathrm{m}^{2}\left(24-45 \mathrm{~kg} / \mathrm{m}^{2}\right)$. Preoperativ kroppsmasseindeks hos disse pasientene var median $54 \mathrm{~kg} / \mathrm{m}^{2}\left(42-88 \mathrm{~kg} / \mathrm{m}^{2}\right)$ og $53 \mathrm{~kg} /$ $\mathrm{m}^{2}\left(42-71 \mathrm{~kg} / \mathrm{m}^{2}\right)$ henholdsvis. Sett i forhold til mediant prosenttap av BMI $>25 \mathrm{~kg} / \mathrm{m}^{2}$,

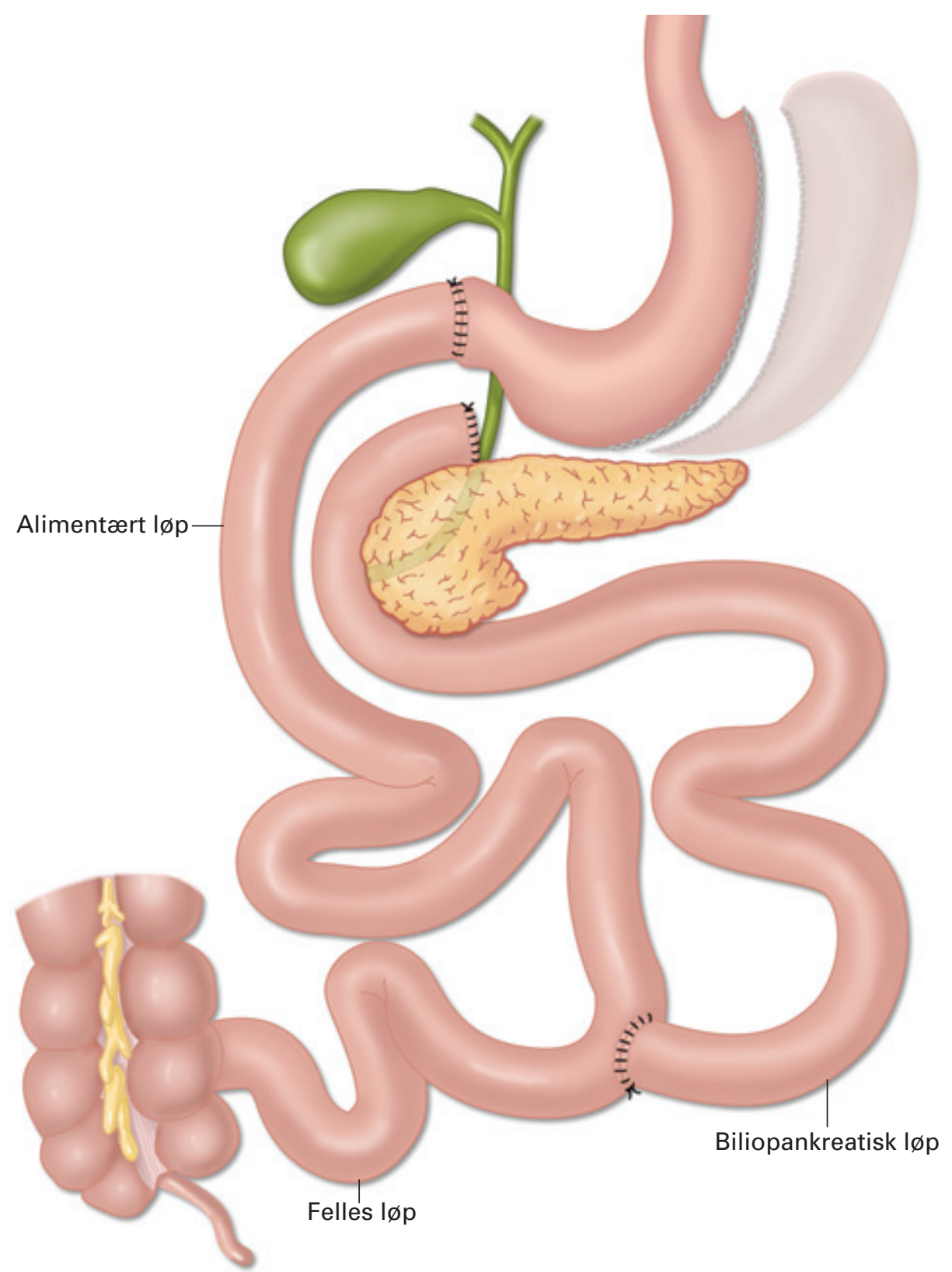

Figur 1 Biliopankreatisk avledning med duodenal omkobling. ๑ Kari Toverud 


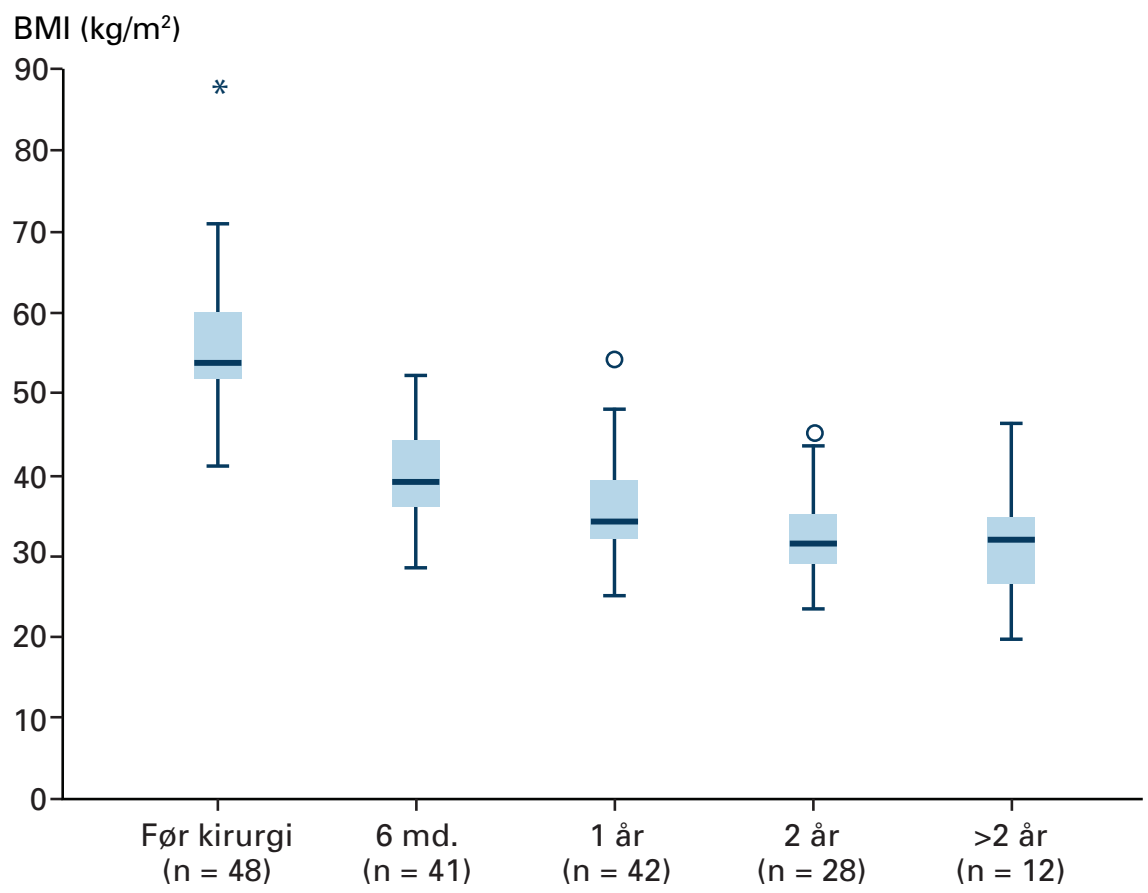

Figur 3 Preoperativ og postoperativ kroppsmasseindeks etter biliopankreatisk avledning med duodenal omkobling. Etter ett og to år møtte henholdsvis 42/45 (93\%) og 28/37 (76\%) av pasientene til tilbudt konsultasjon hos lege eller ernæringsfysiolog. Boksplottene viser median, øvre og nedre kvartil, minimums-og maksimumsverdi samt utenforliggere, sirkler = moderat utenforliggende, asterisk = ekstremt utenforliggende

duksjon av intraabdominalt fett og mindre stiv bukvegg kan bidra til at neste inngrep blir teknisk enklere. Vi tror totrinnsprosedyrer fører til en mer gradvis vektreduksjon idet man skiller det volumreduserende inngrepet på ventrikkelen fra malabsorpsjonen som introduseres senere. Det gir et tryggere grunnlag for å vurdere om pasienten er egnet for duodenal omkobling, og om trinn 2 skal gjennomføres. Det er ikke enighet om bruk av totrinnsprosedyrer og kunnskapsgrunnlaget for å vurdere nytteverdi er begrenset (18).

Det er en fordel for pasienter med sykelig fedme at inngrepet gjennomføres laparoskopisk. Våre pasienter mobiliseres like etter operasjonen uten annen analgetika enn morfinpreparater eller ofte bare mindre potente analgetika. I en randomisert studie hadde pasientene operert med laparoskopisk gastrisk bypass mindre smerter, kortere liggetid og mindre akutte sårproblemer (19) enn etter åpen tilgang. Etter tre år utviklet $5 \%$ av pasientene arrbrokk etter laparoskopisk tilgang mot $39 \%$ etter åpen prosedyre (20).

Et hovedargument for bruk av duodenal omkobling er et større vekttap enn etter andre fedmekirurgiske teknikker som for eksempel gastrisk bypass (8). Vi har deltatt $i$ den eneste randomiserte studien der man sammenlikner vekttapet etter disse to operasjonsteknikkene. I studien var gjennomsnittlig vektreduksjon ett år etter gastrisk bypass og duodenal omkobling henholdsvis $30 \%$ og $41 \%(9,10)$. I en metaanalyse var gjennomsnittlig vektreduksjon etter duodenal omkobling $39 \%$ (1). Vekttapet ved duodenal omkobling må imidlertid veies opp mot en større risiko for ernæringssvikt.

\section{Carl Fredrik Schou (f. 1957)}

er seksjonsoverlege og spesialist i generell og gastroenterologisk kirurgi, Avdeling for gastroenterologisk kirurgi og Senter for sykelig overvekt i Helse Sør-Øst, Oslo universitetssykehus, Aker.

Ingen oppgitte interessekonflikter.

\section{Torgeir T. Søvik (f. 1973)}

har vært lege i spesialisering ved Gastroenterologisk kirurgisk avdeling, og tar nå doktorgrad innen fedmekirurgi ved Senter for sykelig overvekt i Helse Sør-Øst, Oslo universitetssykehus, Aker.

Oppgitte interessekonflikter: Har mottatt $\varnothing$ konomisk støtte til kurs og faglige møter av Johnson \& Johnson og Covidien.

\section{Erlend T. Aasheim (f. 1974)}

er lege med doktorgrad innen fedmekirurgi. Han er Academic Clinical Fellow in Public Health ved University of Cambridge og medisinsk redaktør i Tidsskriftet.

Ingen oppgitte interessekonflikter.

\section{Jon A. Kristinsson (f.1959)}

er spesialist i generell kirurgi og gastroenterologisk kirurgi, han er avdelingsleder, dr.med, Senter for sykelig overvekt i Helse Sør-Øst, Oslo universitetssykehus, Aker.

Ingen oppgitte interessekonflikter.

Pasienter som opereres med duodenal omkobling bør ha gode forutsetninger for å følge opp kosttilskudd og kontrollopplegg. Det er større risiko for vitaminmangler sammenliknet med dem som hadde fått utført gastrisk bypass $(10,11)$. Noen angir hyppigere gastrointestinale bivirkninger, som løs avføring og behov for tettere oppfølging, etter duodenal omkobling sammenliknet med gastrisk bypass.

Det er viktig å definere hvilken behandling som er best for pasientene med særlig høy kroppsmasseindeks. Det er trolig fornuftig à være mer oppmerksom på tilleggsykdommer og livskvalitet etter kirurgi, enn på vekttapet isolert. Det er beskrevet sammenliknbar effekt på tilleggsykdommer og livskvalitet etter gastrisk bypass ved kroppsmasseindeks over og under $50 \mathrm{~kg} / \mathrm{m}^{2}$, selv om mer enn halvparten av pasientene $\mathrm{i}$ den tyngste gruppen hadde BMI $>35 \mathrm{~kg} / \mathrm{m}^{2}$ flere år etter operasjonen (7). En annen studie viser at duodenal omkobling i større grad enn gastrisk bypass bedret diabetes, hypertensjon og dyslipidemi (21).

Laparoskopisk duodenal omkobling er et behandlingstilbud for pasienter med ekstrem sykelig fedme ved Oslo universitetssykehus. Videre evaluering av langtidsresultater og sammenlikning med andre fedmekirurgiske teknikker er nødvendig for å avklare hvilke pasienter som er best egnet for dette inngrepet.

\section{Tom Mala (f. 1968)}

er spesialist i gastroenterologisk kirurgi, overlege dr.med. Han er tilknyttet Avdeling for gastroenterologisk kirurgi og Senter for sykelig overvekt i Helse Sør-Øst, Oslo universitetssykehus, Aker.

Oppgitte interessekonflikter: Har gjennomført reiser til kongresser etc. tidligere der reise har vært støttet av ulike produsenter av kirurgisk utstyr.

\section{Litteratur}

1. Buchwald H, Avidor Y, Braunwald E et al. Bariatric surgery: a systematic review and meta-analysis. JAMA 2004: 292: 1724-37.

2. Sjöström L, Narbro K, Sjöström CD et al; Swedish Obese Subjects Study. Effects of bariatric surgery on mortality in Swedish obese subjects. N Engl J Med 2007; 357: 741 -52.

3. Aasprang A, Andersen JR, Sletteskog $\mathrm{N}$ et al. Helserelatert livskvalitet før og eit år etter operasjon for sjukleg overvekt. Tidsskr Nor Legeforen 2008; 128: 559-62.

4. Aasheim ET, Mala T, Søvik TT et al. Kirurgisk behandling av sykelig fedme. Tidsskr Nor Lægeforen 2007; 127: 38-42

5. Ulset E, Undheim R, Malterud K. Er fedmeepidemien kommet til Norge? Tidsskr Nor Lægeforen 2007; 127: 34-7.

6. Sturm R. Increases in morbid obesity in the USA: 2000-2005. Public Health 2007; 121: 492-6.

7. Suter M, Calmes JM, Paroz A et al. Results of Roux-en-Y gastric bypass in morbidly obese vs superobese patients: similar body weight loss. correction of comorbidities, and improvement of quality of life. Arch Surg 2009; 144: 312-8.

8. Prachand VN, Davee RT, Alverdy JC. Duodenal switch provides superior weight loss in the superobese (BMI > or $=50 \mathrm{~kg} / \mathrm{m} 2)$ compared with gastric bypass. Ann Surg 2006; 244: 611-9. 
9. Søvik TT, Taha O, Aasheim ET et al. Randomized clinical trial of laparoscopic gastric bypass versus laparoscopic duodenal switch for superobesity. Br J Surg 2010; 97: 160-6.

10. Aasheim ET, Björkman S, Søvik TT et al. Vitamin status after bariatric surgery: a randomized study of gastric bypass and duodenal switch. Am J Clin Nutr 2009; 90: 15-22.

11. Tonstad S, Sundfør T, Myrvoll EA. Ernæringsstatus etter operativ behandling for fedme. Tidsskr Nor Lægeforen 2007; 127: 50-3.

12. Deitel M, Gawdat K, Melissas J. Reporting weight loss 2007. Obes Surg 2007; 17: 565-8

13. Buchwald H, Oien DM. Metabolic/bariatric surgery worldwide 2008. Obes Surg 2009; 19: 1605-11.

14. Kim WW, Gagner M, Kini S et al. Laparoscopic vs. open biliopancreatic diversion with duodenal switch: a comparative study. J Gastrointest Surg 2003; 7: 552-7.

15. Ren CJ, Patterson E, Gagner M. Early results of laparoscopic biliopancreatic diversion with duodenal switch: a case series of 40 consecutive patients. Obes Surg 2000; 10: 514-24.

16. Gagner M, Matteotti R. Laparoscopic biliopancreatic diversion with duodenal switch. Surg Clin North Am 2005; 85: 141-9, x-xi.

17. Søvik TT, Aasheim ET, Kristinsson J et al. Establishing laparoscopic Roux-en-Y gastric bypass: perioperative outcome and characteristics of the learning curve. Obes Surg 2009; 19: 158-65.

18. Buchwald H, Kellogg TA, Leslie DB et al. Duodenal switch operative mortality and morbidity are not impacted by body mass index. Ann Surg 2008; 248 : impact 8 .

19. Nguyen NT, Goldman C, Rosenquist CJ et al. Laparoscopic versus open gastric bypass: a randomized study of outcomes, quality of life, and costs. Ann Surg 2001; 234: 279-91.

20. Puzziferri N, Austrheim-Smith IT, Wolfe BM et al. Three-year follow-up of a prospective randomized trial comparing laparoscopic versus open gastric bypass. Ann Surg 2006; 243: $181-8$.

21. Prachand VN, Ward M, Alverdy JC. Duodenal switch provides superior resolution of metabolic comorbidities independent of weight loss in the super-obese $(\mathrm{BMI}>$ or $=50 \mathrm{~kg} / \mathrm{m} 2)$ compared with gastric bypass. J Gastrointest Surg 2010; 14 . 211-20.

Mottatt 9.11. 2010, første revisjon innsendt 16.2. 2011, godkjent 3.6. 2011. Medisinsk redaktør Michael Bretthauer. 